\title{
Discussion on fabrication of Deep Water Gravity Jacket
}

\author{
Sun Ning ${ }^{1, \text { a }}$ Shang Jifei, ${ }^{1, b}$ Yao Dawei ${ }^{1, c}$ \\ ${ }^{1}$ No.492, Lianjiang Road, Qingdao E\&T Development Zone, China \\ a sunning@mail.cooec.com.cn, ${ }^{\mathrm{b}}$ shangjf@mail.cooec.com.cn, ${ }^{\mathrm{c}}$ yaodaw@mail.cooec.com.cn
}

Keywords: Deep water gravity jacket, Fabrication, Buoyancy tanks, Gravity box, Dimension control Abstract. Deep water gravity jacket is a type of offshore steel structure developed in 1970s. Design depth of the type jacket is in 200m and 100 150m water depth is better. Now some foreign countries have the fabrication experience of the type jacket, however there is none fabrication experience in China. This paper describes how to fabricate deep water gravity jacket especially check of bearing capacity of foundation, panels fabrication of jacket, Buoyancy tanks and Gravity box, dimension control, machine and facility and etc., which fills in gaps of fabrication of deep water gravity jacket.

\section{Introduction}

Jacket as a offshore platform for offshore oil and gas exploration generally will be pile foundation type. The type of jacket will be fixed by pile which be penetration to sea bed [1]. The big difference between pile foundation and deep water gravity jacket is that gravity box is designed as gravity jacket foundation and buoyancy tanks is designed on top of jacket to provide buoyancy force. When installation offshore, buoyancy tanks will adjust position of jacket in the sea until putting jacket to the designated location, then fill iron sand into gravity box to fixed jacket. The deep water gravity jacket in this paper is 8 legs jacket. The detail information of jacket shows in the Table 1. And figure 1 shows the 3D model.

Table 1 Detail information of Jacket

\begin{tabular}{|c|c|c|c|c|c|c|c|c|c|}
\hline Name & Legs & $\begin{array}{c}\text { Top } \\
\text { dimension }(\mathrm{m})\end{array}$ & $\begin{array}{c}\text { Bottom } \\
\text { dimension }(\mathrm{m})\end{array}$ & Height $(\mathrm{m})$ & $\begin{array}{c}\text { Water } \\
\text { deep }(\mathrm{m})\end{array}$ & $\begin{array}{c}\text { No. } \\
\text { riser }\end{array}$ & $\begin{array}{c}\text { No. } \\
\text { Caisson }\end{array}$ & $\begin{array}{c}\text { No. } \\
\text { J-tube }\end{array}$ & $\begin{array}{c}\text { Weight } \\
(\mathrm{t})\end{array}$ \\
\hline Jacket & 8 & $40 \times 75$ & $66 \times 66.5$ & 114.3 & 100 & 10 & 1 & 1 & 27500 \\
\hline
\end{tabular}

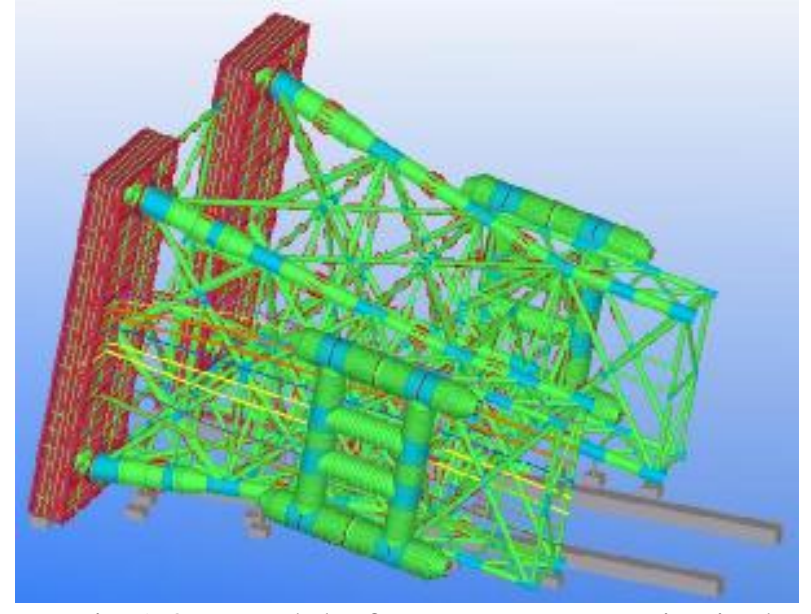

Fig.1 3D model of Deep water gravity jacket

\section{Fabrication yard requirements}

The special structure of gravity jacket causes the design weight of jacket is big, so the fabrication yard requirements are very high. According to the load-out and offshore installation information the jacket will be horizontal built. Figure 2 shows layout of jacket on the fabrication yard. 


\section{layout of launch cradle}

Layout of launch cradle and steel plate for skid way shall meet the requirement of design of launch and skid way. Figure 3 shows the layout of launch cradle. The detail layout requirement as following:

$\ddot{y}$ Layout of steel plate for skid way and connection steel plate and slide block. Welding limited angle steel L100*100*10 inside and outside of skid way.

$\ddot{y}$ Installation of Teflon plate and smear lubricating oil.

$\ddot{y}$ Limited angle steel shall be welding inside and outside of skid way, and the gap between angle steel and timber is $50 \mathrm{~mm}$.

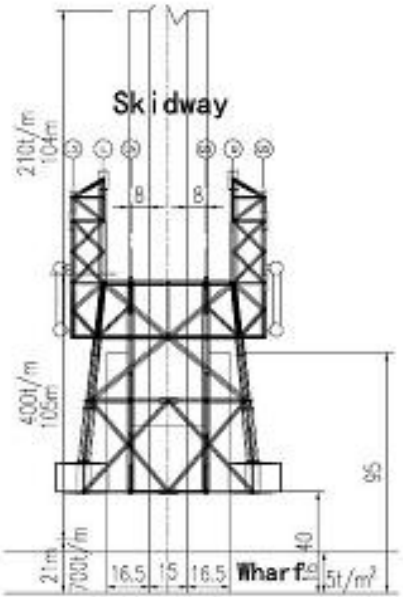

Fig.2 Layout of the Fabrication yard

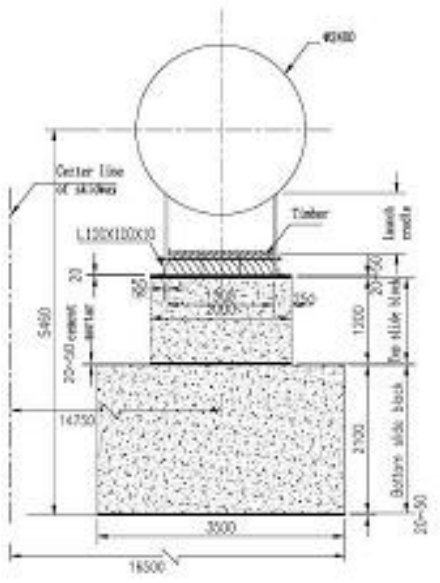

Fig.3 Profile of silde block

\section{Requirements for yard foundation bearing capacity}

According to Loadout Structural Analysis Report [2], the joints in Figure 4 are collected as bearing capacity analysis points. And Figure 5 shows effective length for bearing capacity analysis.

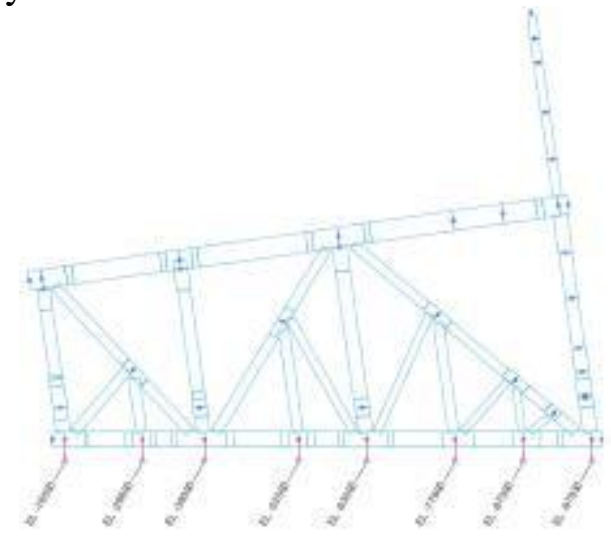

Fig.4 Bearing capacity analysis points

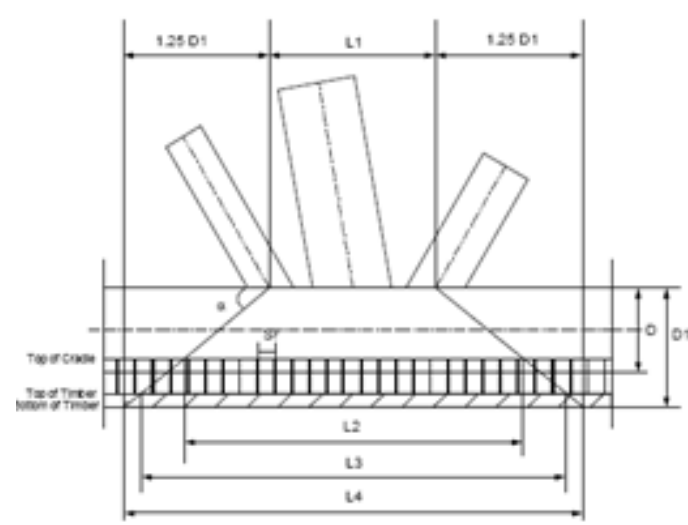

Fig.5 Effective length for bearing capacity analysis According to support reaction of launch cradle @ Row LN and Row QS in condition of fabrication completion and loadout and the effective length for each joints, this paper use rigid connection analysis method[3] to check bearing capacity. The conclusion as following:

$\ddot{y}$ In condition of fabrication completion, the max. load @ Row LN is $288.34 \mathrm{~T} / \mathrm{m}$ which is at EL(-)16.5m. While the max. load @ Row QS is 334.78T/m which is at EL(-)16.5m. Considering the self-weight of slide block, the Max. load of Row LN and QS is $305.84 \mathrm{~T} / \mathrm{m}$ and $352.28 \mathrm{~T} / \mathrm{m}$.

$\ddot{y}$ In condition of loadout, the max. load @ Row LN is $313.68 \mathrm{~T} / \mathrm{m}$ which is at EL(-) $16.5 \mathrm{~m}$. While the max. load @ Row QS is $368.81 \mathrm{~T} / \mathrm{m}$ which is at EL(-)16.5m. Considering the self-weight of slide block, the Max. load of Row LN and QS is $331.18 \mathrm{~T} / \mathrm{m}$ and $386.31 \mathrm{~T} / \mathrm{m}$.

$\ddot{y}$ The bearing capacity $400 \mathrm{~T} / \mathrm{m}$ of yard can meet the fabrication and loadout requirement. 


\section{Fabrication process}

\section{Fabrication process of gravity jacket can be separated the following parts:}

1) Pre-fabrication of main structure and skid shoes;

2) Assembly on skid way;

3) Pre-fabrication and installation of appurtenance such as riser, J-tube and caisson;

4) Pre-fabrication and installation of buoyancy tanks;

5) Pre-fabrication and installation of gravity box;

6) Final painting and inspection;

7) Testing and commissioning.

\section{Fabrication process}

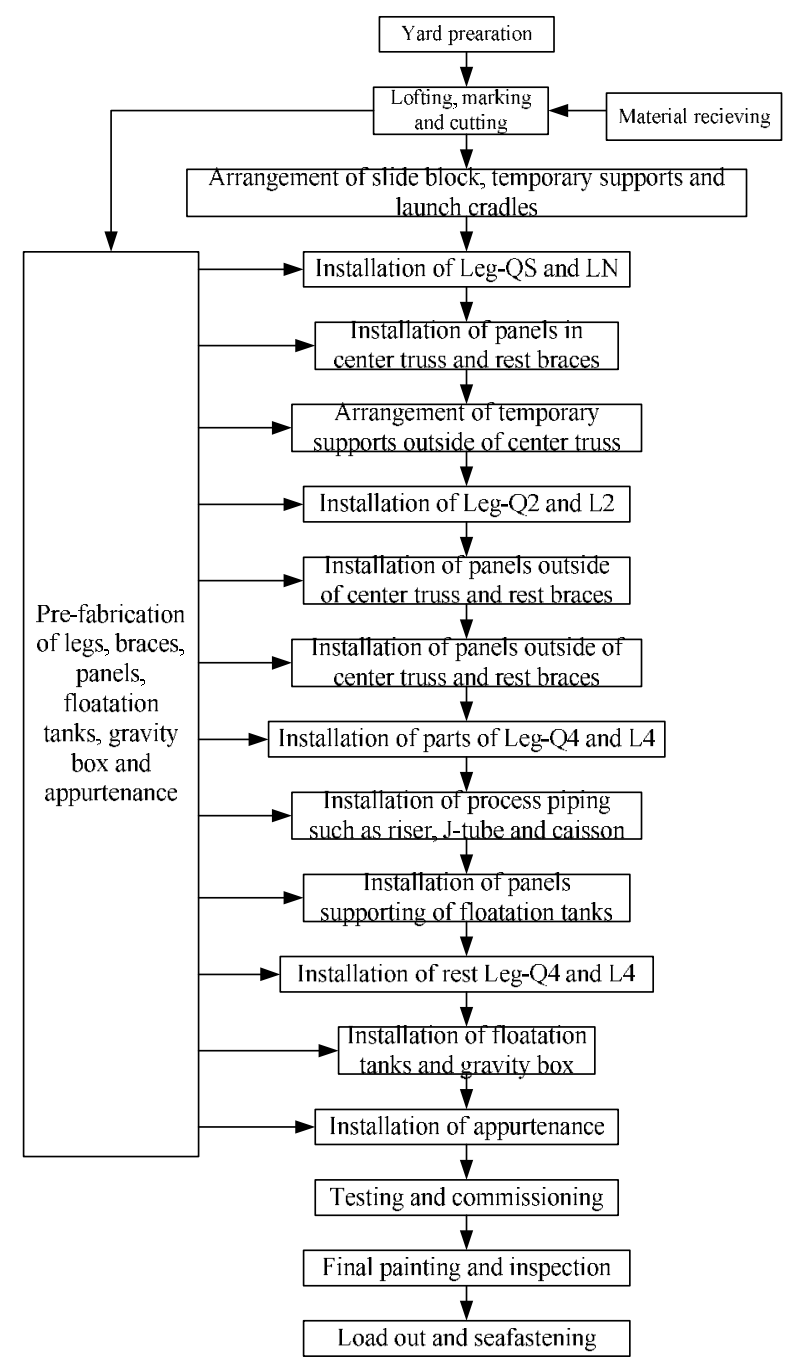

Fig.6 Fabrication process

\section{Description of detail fabrication steps}

\section{Pre-fabrication of legs, vertical and horizontal panels}

$\ddot{y}$ Pre-fabrication of Legs (total 16 pieces):

4 legs @ Row QS and LN will be separated to 2 pieces;

4 legs @ Row Q2, Q4, L2 and L4 will be separated to 2 pieces;

$\ddot{y}$ Pre-fabrication of ring stiffener

$\ddot{y}$ Pre-fabrication of vertical panels

2 vertical panels between EL(-)16500 and EL(-)38000 in the center truss;

4 vertical panels between EL(-)38000 and EL(-)63000 in the center truss; 
2 vertical panels between EL(-)63000 and EL(-)97500 in the center truss;

2 vertical panels between EL(+)13500 and EL(-)16500 outside of the center truss;

2 vertical panels between EL(-)16500 and EL(-)38000 outside of the center truss;

6 vertical panels between EL(-)38000 and EL(-)63000 outside of the center truss;

4 vertical panels between EL(-)63000 and EL(-)97500 outside of the center truss;

2 vertical panels @ Row QN and LS outside of center truss.

$\ddot{y}$ Pre-fabrication of horizontal panels

4 horizontal panels @ EL(-)16500、EL(-)38000、EL(-)63000、EL(-)97500 in the center truss;

4 horizontal panels @ EL(-)16500、EL(-)38000、EL(-)63000、EL(-)97500 outside of the center truss.

$\ddot{y}$ Pre-fabrication of temporary structure such as temporary supports and lifting supporting Pre-fabrication of floatation tanks and gravity box

$\ddot{y}$ Pre-fabrication of floatation tanks

Floatation tanks will be separated to 2 parts refer to figure 7 .

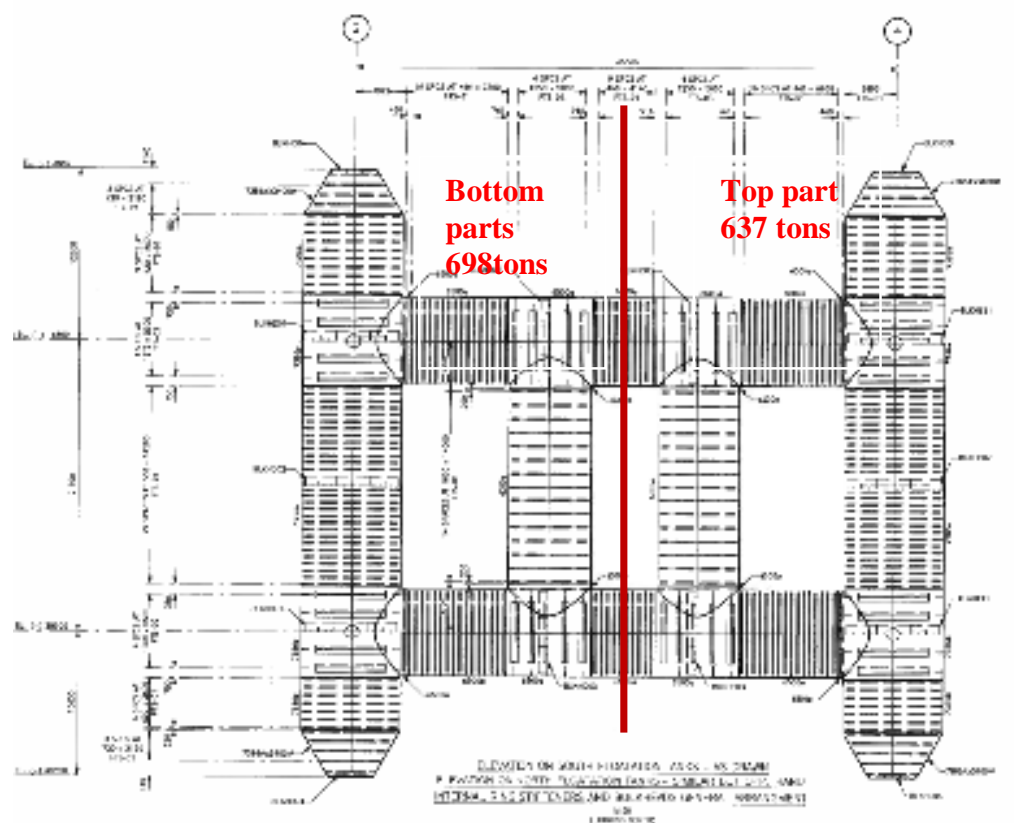

Fig.7 Floatation tank separation

$\ddot{y}$ Pre-fabrication of gravity box

Gravity box will be separated to 4 parts refer to figure 8 . 


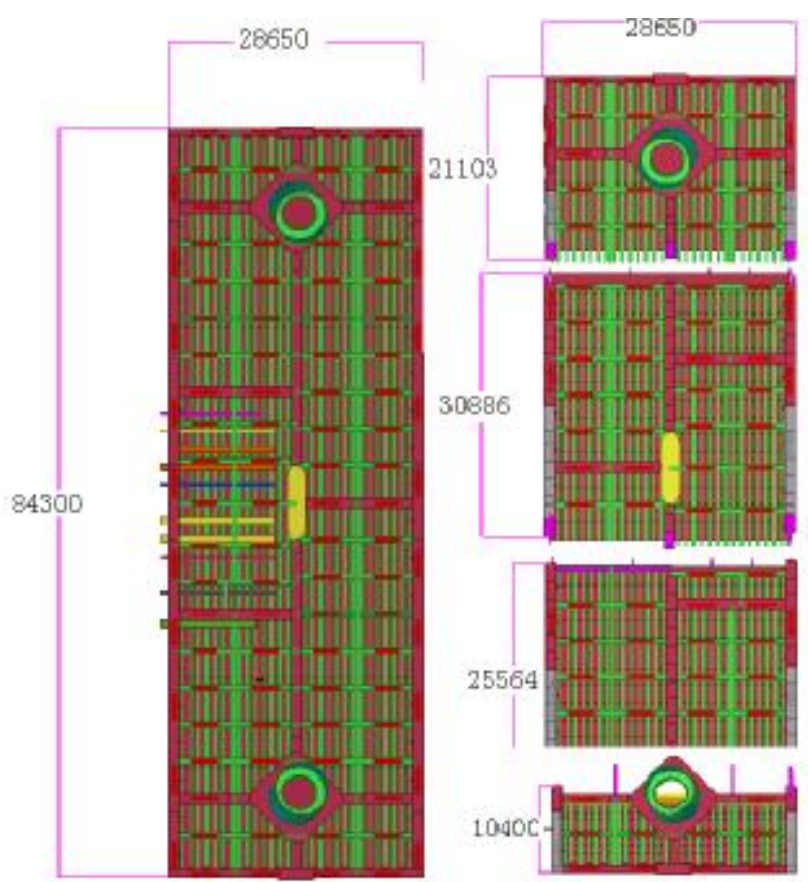

Fig.8 Gravity box separation

\section{Arrangement of temporary supports}

Temporary supports will be separated to 3 types which are supports for legs, gravity box and braces. Supports for floatation tanks are the same as supports for legs. Temporary supports will be welded by filled welding and welding foot is $0.7 \mathrm{t}$ ( $\mathrm{t}$ is the thickness of stiffer plate or check plate). Figure 10 12 show the detail design.

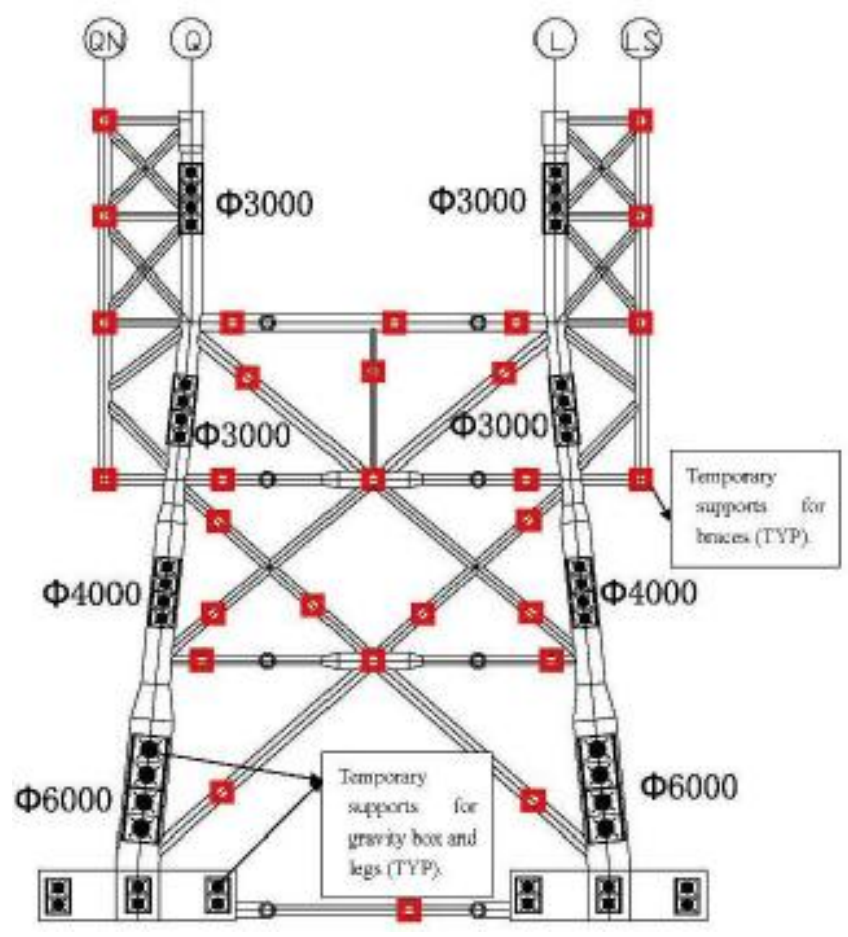

Fig.9 Arrangement for temporary supports

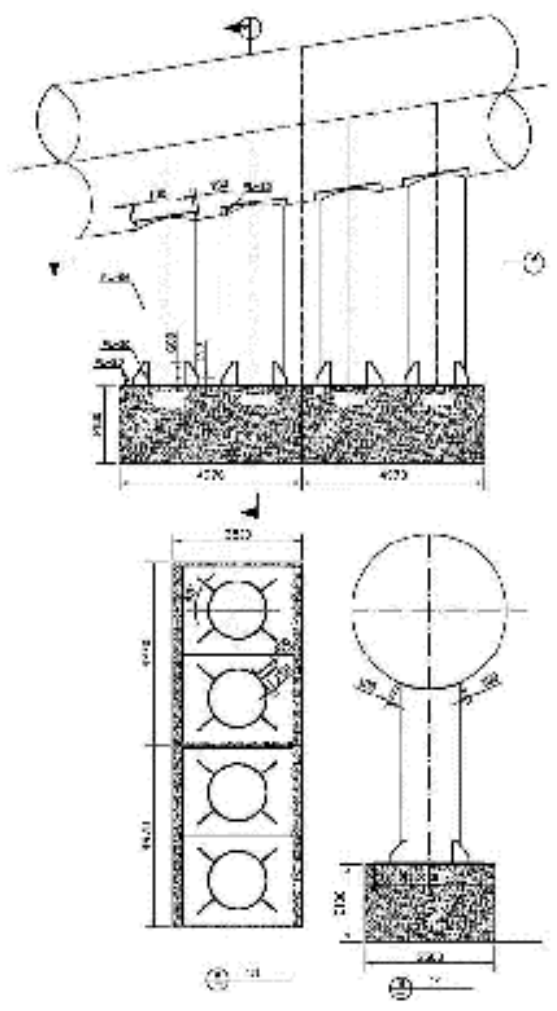

Fig.10 Temporary supports for legs 


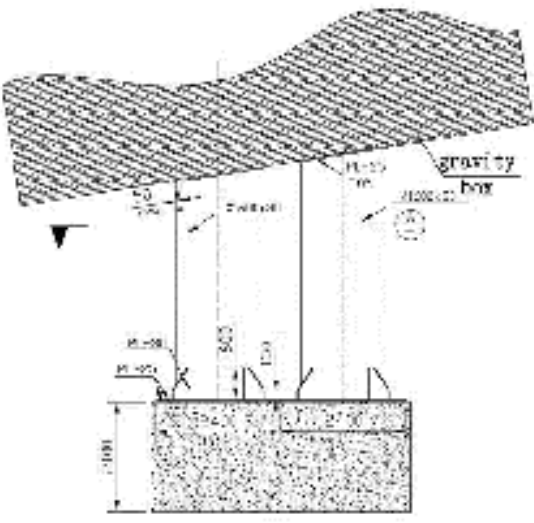

Fig.11 Temporary supports for gravity box

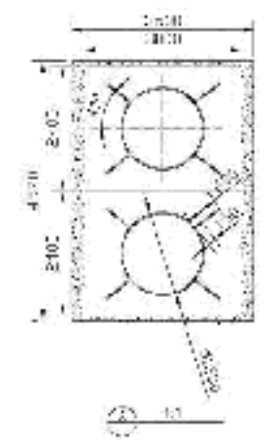

\section{Assembly on skid way}

The assembly sequence of jacket is from top to bottom. Figure 13 18 show the sketch of more important steps of jacket assembly.

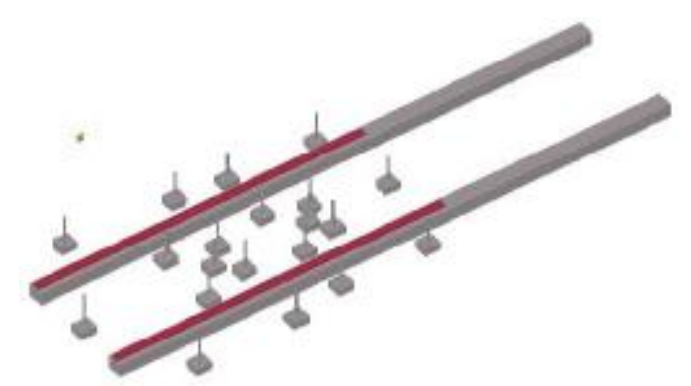

Fig.13 Arrangement of launch cradle and supports

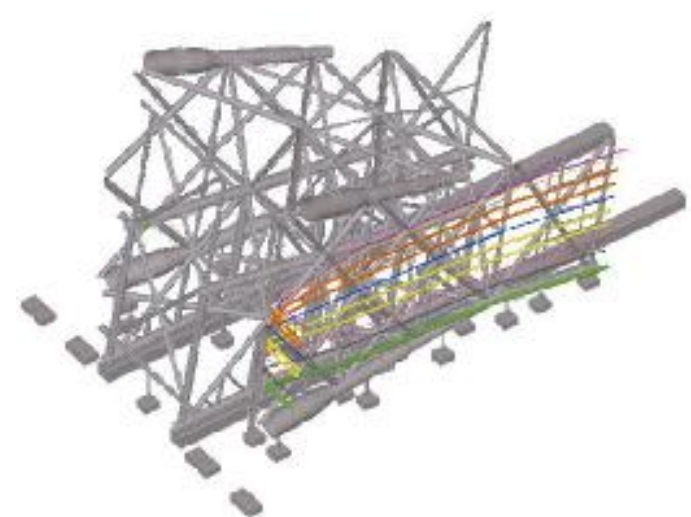

Fig.15 Installation of process piping

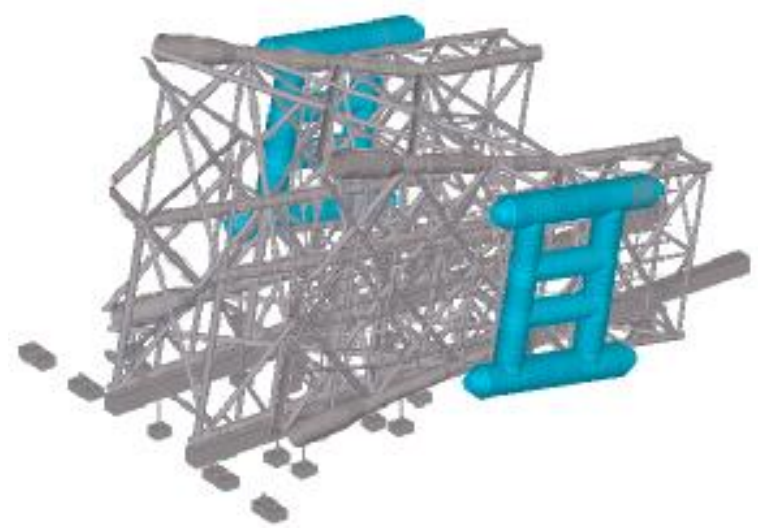

Fig.17 Installation of floatation tanks

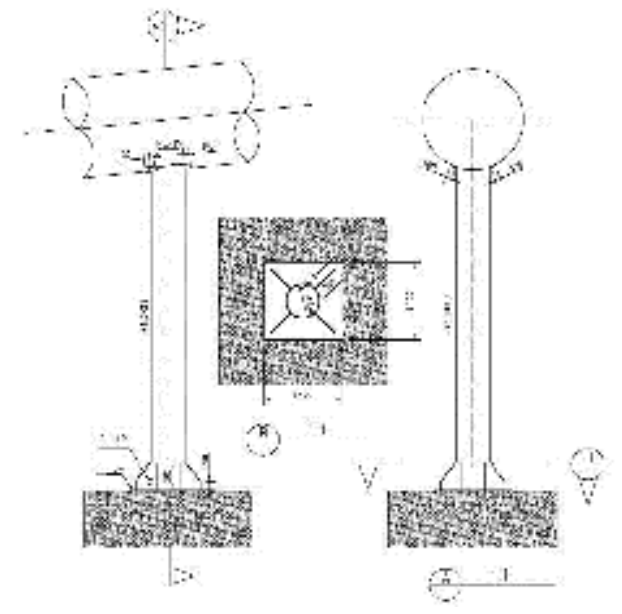

Fig.12 Temporary supports for braces 


\section{Typical lifting}

During assembly lifting and installation is very important especially gravity box. Figure 19 shows the lifting and installation of gravity box. This method can control the structural distortion and use the crane resource sufficiently.
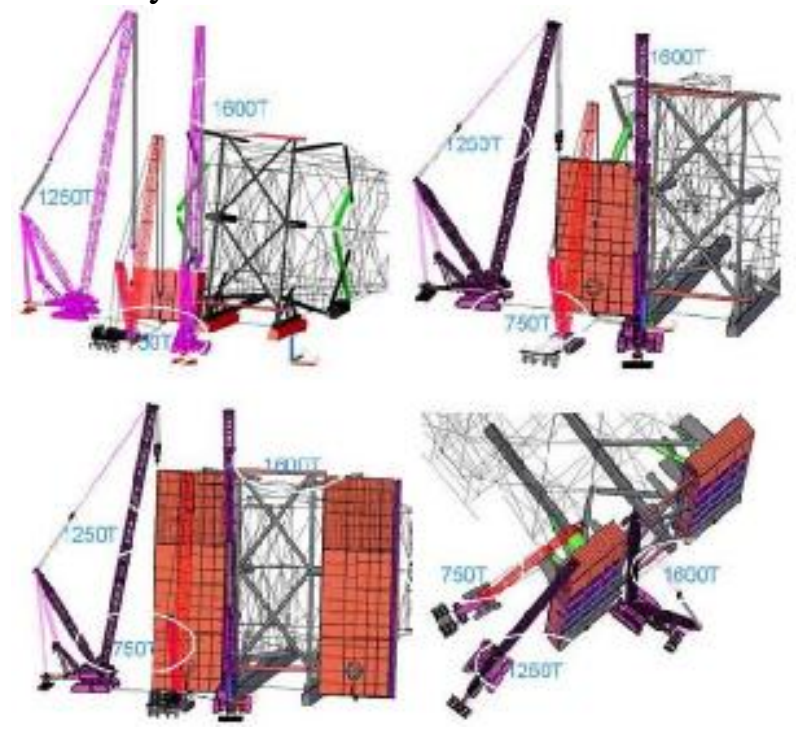

Fig.19 Lifting and installation of gravity box

\section{Dimension control}

For meeting the requirement of technical specification, fabrication of jacket will be performed the following technical requirements[4].

\section{Lofting requirement}

Table 2 Major lofting requirement

\begin{tabular}{|c|c|c|c|c|}
\hline Type & Item & $\begin{array}{l}\text { Standard range } \\
(\mathrm{mm})\end{array}$ & $\begin{array}{l}\text { Limited range } \\
\qquad(\mathrm{mm})\end{array}$ & Marking \\
\hline \multirow{3}{*}{$\begin{array}{l}\text { Cutting } \\
\text { line and } \\
\text { fit up } \\
\text { line }\end{array}$} & $\begin{array}{l}\text { Shape and } \\
\text { dimension }\end{array}$ & \pm 1.0 & \pm 2.0 & \multirow{3}{*}{$\begin{array}{l}\text { White, clear } \\
\text { and legibility }\end{array}$} \\
\hline & Straightness & \pm 1.0 & \pm 1.5 & \\
\hline & $\begin{array}{c}\text { Location } \\
\text { dimension }\end{array}$ & \pm 2.0 & \pm 1.0 & \\
\hline
\end{tabular}

\section{Cutting requirement}

Table 3 Major cutting requirement

\begin{tabular}{|c|c|c|c|c|c|}
\hline \multirow{9}{*}{$\begin{array}{l}\text { Cutting } \\
\text { accuracy } \\
\text { requirement }\end{array}$} & Item & & & $\begin{array}{l}\text { Standard } \\
\text { range }(\mathrm{mm})\end{array}$ & $\begin{array}{l}\text { Limited range } \\
(\mathrm{mm})\end{array}$ \\
\hline & \multirow{6}{*}{$\begin{array}{c}\text { Cutting by } \\
\text { semiautomatic } \\
\text { flame cutting } \\
\text { machine }\end{array}$} & \multicolumn{2}{|c|}{ Rolling direction } & \pm 1.5 & \pm 2.5 \\
\hline & & \multicolumn{2}{|c|}{ Longitudinal } & \pm 2 & \pm 3 \\
\hline & & \multicolumn{2}{|c|}{ Diagonal } & \pm 2 & \pm 3 \\
\hline & & \multirow{3}{*}{ Straightness } & $\mathrm{L} \leq 4 \mathrm{~m}$ & $\leq 1.0$ & $\leq 1.2$ \\
\hline & & & $\begin{array}{l}4 \mathrm{~m}< \\
\mathrm{L} \leq 8 \mathrm{~m}\end{array}$ & $\leq 1.2$ & $\leq 1.5$ \\
\hline & & & $\mathrm{L}>8 \mathrm{M}$ & $\leq 2.0$ & $\leq 2.5$ \\
\hline & \multirow{2}{*}{ Cutting face } & \multicolumn{2}{|c|}{ Roughness } & 0.1 & 0.2 \\
\hline & & \multicolumn{2}{|c|}{ Straightness } & $\leq 1.5$ & $\leq 2.5$ \\
\hline
\end{tabular}




\begin{tabular}{|l|c|c|c|}
\cline { 3 - 4 } \multirow{2}{*}{ Bevel } & Groove depth & \pm 1.5 & \pm 2.0 \\
\cline { 3 - 4 } & Bevel angle & $\pm 2^{\circ}$ & $\pm 4^{\circ}$ \\
\hline
\end{tabular}

Rolling and splice requirement for tubular

Table 4 Major rolling and splice requirement for tubular

\begin{tabular}{|c|c|c|}
\hline Item & & Requirement \\
\hline \multirow{2}{*}{ Straightness } & Any $3000 \mathrm{~mm}$ & $3 \mathrm{~mm}$ \\
\cline { 2 - 3 } & Any $12000 \mathrm{~mm}$ & $10 \mathrm{~mm}$ \\
\cline { 2 - 3 } & Lengths exceeding $12000 \mathrm{~mm}$ & $12 \mathrm{~mm}$ \\
\hline $\begin{array}{c}\text { Radial direction } \\
\text { deviation }\end{array}$ & Longitudinal seams & $3.2 \mathrm{~mm}$ \\
\cline { 2 - 3 } $\begin{array}{c}\text { outside } \\
\text { circumferences } \\
\text { deviation }\end{array}$ & Circumferential welds & Lessor of $0.2 \mathrm{t}$ or $6 \mathrm{~mm}$ \\
\cline { 2 - 3 } & Outside diameter $\leq 605 \mathrm{~mm}$ & $\pm 10 \mathrm{~mm}$ \\
\hline Outside diameter $>605 \mathrm{~mm}$ & $6 \mathrm{~mm}$ \\
\hline
\end{tabular}

\section{Requirement of assembly}

\section{Launch rail}

The dimensional tolerance of launch rail centre lines shall be within $\pm 20 \mathrm{~mm}(3 / 4 \mathrm{in})$ of the theoretical position

and shall also be within $\pm 6 \mathrm{~mm}$ (1/4 in) of its reference elevation. The variation in elevation between any two

points on a launch rail shall not exceed $3 \mathrm{~mm}(1 / 8 \mathrm{in})$ within any $3 \mathrm{~m}(10 \mathrm{ft})$.

\section{Global horizontal tolerances}

The global tolerances for leg spacing at plan bracing levels are detailed below:

a) The horizontal centre to centre distance between adjacent legs at the top of a structure where a deck or other structure is to be placed (stab-in nodes) shall be within $10 \mathrm{~mm}$ ( $3 / 8 \mathrm{in}$ ) of the design values;

b) The horizontal centre-to-centre distance between legs at other locations shall be within $20 \mathrm{~mm}(3 / 4$ in) of the design values;

c) The horizontal centre-to-centre diagonal distances between legs at the top of a structure where a deck or other structure is to be placed (stab-in nodes) shall be within $10 \mathrm{~mm} \mathrm{(3/8} \mathrm{in)} \mathrm{of} \mathrm{the} \mathrm{design}$ values;

d) The horizontal centre-to-centre diagonal distance between legs at other locations shall be within 20 $\mathrm{mm}(3 / 4 \mathrm{in})$ of the design values.

\section{Global vertical tolerances}

The global tolerances for vertical levels of plan bracing are as detailed as follows:

a) The elevation of plan bracing levels shall be within $13 \mathrm{~mm}(1 / 2 \mathrm{in})$ of the design values;

b) The vertical level of braces within a horizontal plane shall be within $13 \mathrm{~mm}(1 / 2 \mathrm{in})$ of the design values;

c) The vertical distance between plan bracing elevations shall be within $13 \mathrm{~mm}(1 / 2 \mathrm{in})$ of the design values.

\section{Other requirements}

Any other requirements herein not description shall refer to ISO 199022007.

\section{Major equipment and facility and auxiliary materials}

Major equipment and facility: crawler crane, winch, trailer, jack, wirerope and etc.

Major crane as following: 
Table 5 Major cranes

\begin{tabular}{|l|l|l|l|l|}
\hline Item & Name & Capacity & Quantity & Remark \\
\hline 1 & Manitowoc 16000 & 400T & 2 & \\
\hline 2 & Liebherr 1400 & 400T & 2 & With counterweight \\
\hline 3 & Manitowoc 18000 & $750 \mathrm{~T}$ & 2 & With counterweight \\
\hline 4 & DEMAG CC8800 & 1250T & 1 & With counterweight \\
\hline
\end{tabular}

\section{Auxiliary materials}

\section{Auxiliary materials for temporary support}

Table 6 Auxiliary materials for temporary support

\begin{tabular}{|c|c|c|c|c|c|c|}
\hline I t e m & Na me & Specification(mm) & Ma teri a l & Quantity & $\begin{array}{c}\text { Gross } \\
\text { Wegiht }(\mathrm{t})\end{array}$ & Remark \\
\hline 1 & Plate & $\mathrm{PL} 50 \times 3000 \times 11000$ & GB 712-2000 D36 & 28 & 362.670 & \\
\hline 2 & Plate & $\mathrm{PL} 32 \times 3000 \times 12000$ & GB 712-2000 D36 & 8 & 72.346 & \\
\hline 3 & Plate & $\mathrm{PL} 25 \times 3000 \times 12000$ & GB 712-2000 D36 & 110 & 777.150 & \\
\hline 4 & Plate & $\mathrm{PL} 28 \times 2500 \times 12000$ & GB 712-2000 D36 & 12 & 79.128 & \\
\hline 5 & Pl ate & PL $20 \times 3000 \times 12000$ & GB 712-2000 D36 & 25 & 141.300 & \\
\hline & & & sum & 183 & 1432.594 & \\
\hline
\end{tabular}

\section{Auxiliary materials for scaffolding}

Table 7 Auxiliary materials for scaffolding

\begin{tabular}{|c|c|c|c|c|c|c|c|c|c|c|c|c|c|}
\hline \multirow{2}{*}{$\frac{\text { Item }}{1}$} & \multirow{2}{*}{$\frac{\text { Na me }}{\text { Plate }}$} & \multicolumn{8}{|c|}{ Specification(mm) } & \multirow{2}{*}{$\begin{array}{c}\text { Ma t e r i a l } \\
\text { GB712-2000 D36 }\end{array}$} & \multirow{2}{*}{$\frac{\text { Quant it y }}{8}$} & \multirow{2}{*}{$\begin{array}{c}\begin{array}{c}\text { Gross } \\
\text { Weight(t) }\end{array} \\
42.390\end{array}$} & \multirow[t]{2}{*}{ Remark } \\
\hline & & $\mathrm{PL}$ & 25 & $\mathrm{x}$ & 3000 & $\mathrm{x}$ & & $\mathrm{x}$ & 9000 & & & & \\
\hline 3 & H.steel & $\mathrm{H}$ & 200 & $\mathrm{x}$ & 200 & $\times 8$ & $\times 12$ & $\mathrm{x}$ & 12000 & GB/T 700-1988 Q235B & 300 & 175.428 & \\
\hline \multirow[t]{2}{*}{5} & Rod & $\Phi$ & 25 & $x$ & & $x$ & & $\mathrm{x}$ & 12000 & HRB400 & 8 & 0.370 & \\
\hline & & & & & & & & & & sum & 316 & 218.188 & \\
\hline
\end{tabular}

\section{Auxiliary materials for lifing}

Table 8 Auxiliary materials for lifting

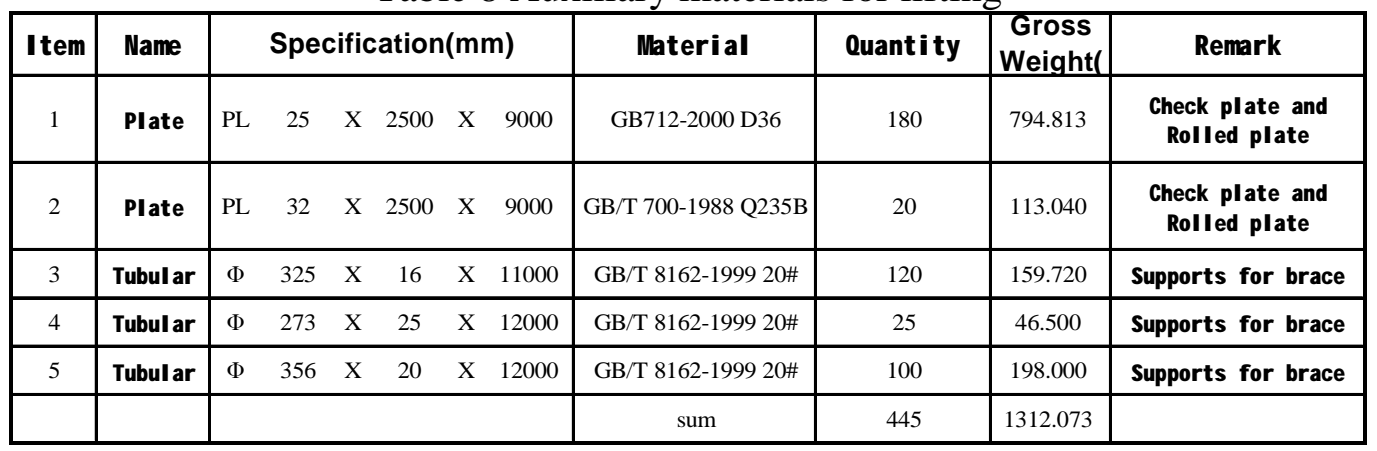

\section{Gauging for Risers}

Table 9 Gauging for Risers

\begin{tabular}{|c|c|c|c|}
\hline I t e m & Na me & Specification & Ouantity \\
\hline 1 & buckle detector & QQP. 8" & 1 \\
\hline 2 & buckle detector & QQP-10" & 2 \\
\hline 3 & buckle detector & QQP-14" & 1 \\
\hline 4 & buckle detector & QQP. 20" & 1 \\
\hline 5 & buckle detector & QQP-28" & 4 \\
\hline 6 & buckle detector & QQP-42" & 1 \\
\hline 7 & gauging plate & 8" & 2 \\
\hline 8 & gauging plate & $10 "$ & 4 \\
\hline 9 & gauging plate & $14 "$ & 2 \\
\hline 10 & gauging plate & 201 & 2 \\
\hline 11 & gauging plate & $281 "$ & 8 \\
\hline 12 & gauging plate & $42^{\prime \prime}$ & 2 \\
\hline
\end{tabular}




\section{Conclusions}

This paper describes fabrication process of deep water gravity jacket, checking bearing capacity of foundation, arrangement of temporary supports, dimension control, fabrication of floatation tanks and gravity box and equipment, facility and auxiliary materials involved in the construction which can provide good fabrication experience and reference of this type or similar jacket.

\section{References}

[1] Zhang Wanpeng: Installation and attention Problems of Petrol Pipe-Platform on the Sea.China Offshore Platform Vol.23 No.4 Aug, 2008

[2] Jacket loadout structural analysis report JC6640RS10001008 Rev.0 Dec. 2011.

[3] Code for design of building foundation GB 50007-2001.

[4] Petroleum and natural gas industries-Fixed steel offshore structures ISO19902 2007 